\title{
Vulnerabilidade ao Estresse entre Agentes de Segurança Penitenciários
}

\author{
Sara Rodrigues de Jesus ${ }^{1}$ \\ ${ }^{1}$ Psicóloga, Juiz de Fora, MG, Brasil.
}

\author{
Andreia Monteiro Felippe ${ }^{2}$ \\ ${ }^{2}$ Centro Universitário Academia, Juiz de Fora, MG, Brasil.
}

\author{
Yury Vasconcellos da Silva ${ }^{2}$ \\ ${ }^{2}$ Centro Universitário Academia, Juiz de Fora, MG, Brasil.
}

Resumo: As atividades do Agente de Segurança Penitenciário podem torná-lo vulnerável ao estresse, devido a fatores como pressão por trabalho em longos turnos, ambiente tenso e constante exposição ao perigo. Trata-se de uma pesquisa de campo, de viés quantitativo, descritivo, comparativo e correlacional, com o objetivo de avaliar a vulnerabilidade ao estresse entre Agentes de Segurança Penitenciários de uma unidade prisional do interior de Minas Gerais. Foram aplicados os instrumentos: entrevista estruturada, seguida de "Escala deVulnerabilidade ao Estresse no Trabalho”. A amostra foi de 95 Agentes de Segurança Penitenciários que mantêm contato direto com os presos. Foram obtidos os seguintes resultados: a) no geral, a "vulnerabilidade ao estresse" nos Agentes de Segurança Penitenciários da unidade prisional foi dada como superior em $53,7 \%$ da amostra; b) quanto ao "clima e funcionamento organizacional", a classificação foi médio superior; c) no fator "pressão no trabalho", a vulnerabilidade foi médio superior; d) quanto ao fator "infraestrutura e rotina", a vulnerabilidade foi classificada como superior em 70,5\% dos agentes. Foi constatado que os solteiros têm maior vulnerabilidade ao estresse em todos os fatores pesquisados. Concluiu-se que os Agentes de Segurança Penitenciários da unidade prisional do interior de Minas Gerais estão vulneráveis ao estresse, devendo ser elaboradas políticas públicas para combater o fenômeno.

Palavras-chave: Estresse, Trabalho, Escala de vulnerabilidade ao estresse no trabalho, Agente de Segurança Penitenciário.

\section{Vulnerability to Stress in Penitentiary Security Agents}

\begin{abstract}
Penitentiary Security Agent activities can make them vulnerable to stress due to factors such as pressure for working long hours, tense environment and a continuous hazard exposure. This is a field research of quantitative bias, descriptive, comparative and correlational, with the objective of assessing the vulnerability to stress of Penitentiary Security Agents of a Prison Unit in the interior of Minas Gerais. The instruments which were applied were: structured interview followed by "Workplace Stress Scale". The sample was of 95 Penitentiary Security Agents who deal directly with the prisoners. The results obtained were: a) in general, vulnerability to stress in Penitentiary Security Agents of the Prison Unit was demonstrated superior in 53.7\% of the agents; b) regarding the climate and organizational functioning, the classification was median superior; c) in the factor Pressure at workplace, the vulnerability was median superior; d) regarding the factor Infrastructure and Routine, the vulnerability was classified as superior in $70.5 \%$ of the Agents. It was found that single Agents are more vulnerable to stress in all of the researched factors. It was concluded that prison security agents of a prison unit in the interior of Minas Gerais are vulnerable to stress, and public policies should be developed in order to combat the actual phenomenon.
\end{abstract}

Keywords: Stress, Work, Workplace stress scale, Penitentiary Security Agent. 


\title{
Vulnerabilidad al Estrés en los Agentes de Seguridad Penitenciarios
}

\begin{abstract}
Resumen: Las actividades del Agente de Seguridad Penitenciario pueden volverlo vulnerable al estrés debido a factores comola presión por trabajar por largos turnos, ambiente tensoy constante exposición al peligro. Se trata de una investigación de campo, de sesgo cuantitativo, descriptivo, comparativo y correlacional, con objetivo de evaluar la vulnerabilidad al estrés de los Agentes de una Unidad Penal del interior de Minas Gerais. Fueron aplicados los siguientes instrumentos: entrevista estructurada, seguida de "Escala de Vulnerabilidad al Estrés en el Trabajo". La muestra fui de 95 Agentes que mantienen contacto. Fueron obtenidos los siguintes resultados: a) en el general, la vulnerabilidad al estrés de los Agentes de la Unidade Penal fue dada como superior en el 53,7\% de la muestra; b) en relación con el Ambiente y Funcionamiento Organizacional, la clasificación fue medio superior; c) en el factor Presión Laboral, la vulnerabilidad fue medio superior; d) en cuanto al factor Infraestructura y Rutina, la vulnerabilidad fue clasificada como superior en el 70,5\% de los Agentes. Se constató que los Agentes solteros possen mayor vulnerabilidad al estrés en todos los factores investigados. Se concluyó que los Agentes de la Unidade Penal analizada están vulnerables al estrés, haciéndose necesarias políticas públicas para combatir el fenómeno.
\end{abstract}

Palabras clave: Estrés, Trabajo, Escala de vulnerabilidad al estrés en el trabajo, Agente de Seguridad Penitenciario.

\section{Introdução}

O presente estudo averiguou a vulnerabilidade ao estresse dos Agentes de Segurança Penitenciários (ASP) de uma unidade prisional (UP) do interior de Minas Gerais. Sabe-se que a constante exposição ao perigo, ao estado de alerta, à pressão/tensão, somada à periculosidade e à insalubridade do ambiente de trabalho, constituem variáveis relevantes para o surgimento de sintomas do estresse. Embora grande parte dos estudos realizados no Brasil tenha investigado as condições de saúde dos encarcerados, pouco se investigou sobre a temática envolvendo os ASP. Ainda que analisados a partir de aspectos relacionados à saúde, educação e trabalho, o ASP aparece de forma secundária no contexto mais amplo do sistema penal (Cruz, Batitucci, Silva, \& Souza, 2013; Lourenço, 2010; Moraes, 2013).

Com o objetivo de avaliar a vulnerabilidade ao estresse entre ASP, abordar a temática do estresse no trabalho e refletir sobre seus efeitos nas atividades laborais desses agentes, foram avaliadas as seguintes variáveis: Clima e funcionamento organizacional; Pressão no trabalho; Infraestrutura e rotina. Também se verificou as relações entre as variáveis clínicas, sociais e ocupacionais dos agentes e as variáveis apontadas na Escala de Vulnerabilidade ao Estresse no Trabalho (EVENT).
Atual e relevante do ponto de vista científico e social, o tema contribui para debates sobre a vulnerabilidade ao estresse e para futuros estudos e intervenções junto aos ASP, buscando formas de prevenção e minimização dos impactos em sua saúde física e psíquica. O estudo se justifica ainda do ponto de vista humanitário e ético político, considerando o terceiro lugar ocupado pelo Brasil no ranking mundial de aprisionamentos e as crescentes taxas de hiperencarceramento, conforme o Levantamento Nacional de Informações Penitenciárias (Santos \& Rosa, 2017a). Nesse sentido, a temática também busca refletir sobre o atual quadro carcerário brasileiro e suas implicações na saúde e contribuições para a vulnerabilidade ao estresse em ASP.

\section{Estresse no trabalho}

Embora o trabalho seja relevante para o desenvolvimento individual, assumindo diferentes significados e consequências para cada trabalhador, pode também acarretar o comprometimento da saúde física e mental, em virtude da submissão ao sofrimento, ao desgaste e à tensão. Assim, um local de satisfação das necessidades de subsistência pode ocasionar o comprometimento da saúde física, mental e psicológica do trabalhador (Goulart Júnior \& Lipp, 2011). 
Reis, Fernandes e Gomes (2010) destacam a existência de modelos teóricos específicos, predominando a abordagem clínica, que explica o fenômeno do estresse ocupacional decorrente da percepção individual de desajustes entre as demandas do ambiente e a capacidade de respostas do indivíduo. A importância de fatores individuais que interagem com o ambiente de trabalho, por meio de fatores organizacionais estressores, é consenso entre os estudos (Andrade, 2013; DuBrin, 2003; Goulart Júnior \& Lipp, 2011; Greenberg, 2002; Guimarães \& Freire, 2004; Leka, Griffiths, \& Cox, 2003; Robbins, 2002; Sisto, Baptista, \& Noronha, 2007; Sousa, Mendonça, Zanini, \& Nazareno, 2009). Assim, deve-se compreender o fenômeno de forma global e contextualizada.

Diferentes funções e cargos favorecem o desencadeamento de sintomas do estresse, principalmente quando o profissional tem contato direto com problemas de terceiros. Os conflitos entre papéis geram expectativas, possibilitando a insatisfação no contexto organizacional (Genuíno, Gomes, \& Moraes, 2009; Greenberg, 2002; Reis et al., 2010; Robbins, 2002; Sisto et al., 2007; Stoner \& Freeman, 1999; Zanelli, 2010).

Santos (2007) menciona que a profissão do trabalhador penitenciário está ligada a diferentes formas de discriminação, preconceitos e mitos que permeiam o imaginário humano e que impedem a percepção da complexidade do real trabalho executado. A sociedade imprime suas marcas de acordo com suas concepções e critérios e as transferem ao ASP, que em vez de refutá-las, as internaliza, potencializando seus efeitos. Esses profissionais percebem a falta de reconhecimento da população sobre seu papel (Bonez, Sehnem, \& Moro, 2013).

Estendendo-se em turnos longos, com excesso de horas de trabalho e acentuada tensão do ambiente, as atividades do ASP estão entre as mais estressantes do mundo (Araújo Filho, 2010). O contato diário com o preso, além de expor os agentes a intimidações, agressões, ameaças e rebeliões, correndo risco de tornarem-se reféns ou de morrerem, sujeita-os a prejuízos à saúde física e mental, tornando-os vulneráveis a situações potenciais geradoras de estresse. Além disso, ruídos, temperaturas, vibrações, iluminação e poluição são estressores produzidos nesse ambiente de trabalho (Bonez et al., 2013; Chiavenato, 2004; Codo, Saratto, \& Vasquez-Menezes, 2004; Fernandes et al., 2002; Greenberg, 2002; Ladeira, 1996; Paschoal \& Tamayo, 2004; Saldaña, Menotti, Garavito, \& Muñoz, 2010; Sisto et al., 2007).
É necessário ainda refletir, dentro do contexto da saúde e estresse do ASP, sobre a realidade do sistema prisional brasileiro, marcado pelo superencarceramento, além da presença de facções e grupos criminosos organizados. Esse fenômeno tem crescido nas últimas décadas, merecendo atenção por imprimir padrões de comportamentos e violência, disseminando medo dentro e fora das prisões. Ademais, domina a maioria dos internos, provoca fugas, mortes e rebeliões, gerando tensionamento em todo o funcionamento penitenciário (Salla, Dias, \& Silvestre, 2012).

Do ponto de vista organizacional, a superpopulação prisional e a carência de funcionários são intensificadoras do desgaste físico e mental no cotidiano dos ASP. A insatisfação no trabalho pode aumentar devido à falta de suporte de liderança e escassez de meios humanos e materiais (Cruz et al., 2013; Kurowski \& Moreno-Jiménez, 2002; Lopes, 2002; Rumin, 2006), levando-os a exercerem funções variadas, repetitivas e estressantes, o que favorece a manifestação de síndromes, doenças e sintomas relacionados ao trabalho (Correia, 2006; Duarte, 2010; Lourenço, 2010).

Isso posto, em virtude de vários casos de afastamento do trabalho por desgastes emocionais ou outros fatores relacionados ao cotidiano da profissão, a saúde mental do ASP tem despertado preocupação (Rumin, 2006).

\section{Método}

Trata-se de uma pesquisa de campo, realizada por meio de um estudo transversal, com abordagem quantitativa, que analisou algumas características do estresse entre ASP. As relações das variáveis sociodemográficas e de trabalho com a Escala de Vulnerabilidade ao Estresse no Trabalho (EVENT) foram investigadas por meio de estudos comparativos, utilizando-se o teste T e ANOVA. Para a análise relacional, adotou-se o teste qui-quadrado e de correlação de Pearson.

\section{Participantes}

A pesquisa foi realizada em uma UP do interior de Minas Gerais, destinada a acolher presos provisórios. A equipe da UP era composta por 176 funcionários, com as seguintes funções: Diretor Geral, Diretor de Segurança, Diretor de Atendimento, Diretor Administrativo, Assessoria de Inteligência, Técnico de Informática, Assessoria de Comunicação e Técnicos de Enfermagem. Além desse efetivo, a UP contava com 
psicólogos, assistentes sociais, dentistas, médicos, salas da Ordem dos Advogados do Brasil (OAB) e da Defensoria Pública, refeitórios e uma unidade de trabalho de detentos, todas construídas pelos internos.

Os critérios de inclusão adotados foram: ASP de ambos os sexos, contratados ou concursados da UP que exerciam funções diretamente ligadas ao preso (Tabela 1).

Tabela 1

Descrição das principais funções exercidas pelos Agentes de Segurança Penitenciários.

\begin{tabular}{|c|c|}
\hline Canil & $\begin{array}{l}\text { Treinar, condicionar e cuidar dos } \\
\text { cães da UP; acompanhar a rotina } \\
\text { do preso, juntamente com o cão, } \\
\text { em momentos de saídas das celas e } \\
\text { revistas de segurança. }\end{array}$ \\
\hline $\begin{array}{l}\text { Coordenador } \\
\text { de segurança }\end{array}$ & $\begin{array}{l}\text { Fornecer o apoio à diretoria de } \\
\text { segurança; coordenar as atividades } \\
\text { dos demais agentes penitenciários. }\end{array}$ \\
\hline $\begin{array}{l}\text { Externo/ } \\
\text { obras }\end{array}$ & $\begin{array}{l}\text { Acompanhar e realizar a vigilância } \\
\text { do detento quando este exerce } \\
\text { atividade laborativa dentro da UP. }\end{array}$ \\
\hline GIR & $\begin{array}{l}\text { Solucionar conflitos e intervenções } \\
\text { para a manutenção da ordem na UP. }\end{array}$ \\
\hline GTI & $\begin{array}{l}\text { Transportar o preso dentro da UP; } \\
\text { inspecionar as celas; conferir as } \\
\text { grades e abrir e fechar as celas para } \\
\text { o "banho de sol". }\end{array}$ \\
\hline GTE & $\begin{array}{l}\text { Transportar o detento fora da UP. } \\
\text { Diferencia-se da escolta, pelo fato de } \\
\text { fazer o transporte do preso a outras } \\
\text { instituições, como o fórum local } \\
\text { para a realização de audiências. }\end{array}$ \\
\hline $\begin{array}{l}\text { Inspetor de } \\
\text { plantão }\end{array}$ & $\begin{array}{l}\text { Exerce a mesma função de um } \\
\text { plantonista, diferenciando-se } \\
\text { por liderar um grupo específico e } \\
\text { assumir a responsabilidade da UP } \\
\text { em dias/horários sem expediente. }\end{array}$ \\
\hline Motorista & $\begin{array}{l}\text { Realizar o transporte dos } \\
\text { funcionários da UP; entregar } \\
\text { documentos e transportar o preso } \\
\text { dentro da UP. }\end{array}$ \\
\hline Muralha & $\begin{array}{l}\text { Vigilância interna e externa da UP } \\
\text { e dos arredores dos muros da UP; } \\
\text { observar a rotina do preso. }\end{array}$ \\
\hline Plantonista & $\begin{array}{l}\text { Exercer todas as atividades na UP } \\
\text { em escala de plantão ( } 24 / 72 \text { horas). }\end{array}$ \\
\hline Portaria & $\begin{array}{l}\text { Vigilância interna e externa da } \\
\text { unidade; fazer o primeiro contato } \\
\text { com o detento, receber os familiares, } \\
\text { visitas, revistas e advogados. }\end{array}$ \\
\hline
\end{tabular}

Foram aplicados os seguintes critérios de exclusão: função de direção, chefias sem contato direto com o preso e só funções administrativas. Dos 176 funcionários da UP, 158 foram incluídos nesta pesquisa, dos quais 14 não participaram por diversos motivos (demissão, afastamento por doença, férias), restando 144 agentes, dos quais 119 foram entrevistados. Doze recusaram-se a participar, portanto, os instrumentos foram aplicados em 107 ASP. Outros 12, embora tenham concordado assinando o Termo de Consentimento Livre e Esclarecido (TCLE), evidenciaram receio quanto ao objetivo da pesquisa, demonstrando que as respostas assinaladas não correspondiam ao que realmente pensavam. Isso também ser comprovado na aplicação do EVENT, quando assinalaram apenas uma opção no caderno de respostas. Para evitar tendências nos resultados, essas 12 entrevistas não foram consideradas. O total da amostra válida foi, portanto, de 95 ASP, valor considerável comparado ao tamanho da população válida (144), ocasionando por sua vez uma margem de erro pequena $(\mathrm{E}=1,27$ com $95 \%$ de confiança).

\section{Instrumentos}

Para avaliar a vulnerabilidade ao estresse no trabalho do ASP, foram aplicados dois instrumentos: entrevista estruturada, contendo variáveis sociodemográficas e clínicas, além de variáveis relacionadas ao trabalho (idade, estado civil, escolaridade, tempo de exercício na função, uso de medicação contínua, vício, tratamento de saúde, afastamento do trabalho por motivo de doença); e Escala de Vulnerabilidade ao Estresse no Trabalho (EVENT). Desenvolvida e validada por Sisto et al. (2007), e aprovada pelo Conselho Federal de Psicologia, a referida escala avalia a influência das situações rotineiras ocupacionais sobre o comportamento dos indivíduos, caracterizando três fatores relacionados ao ambiente de trabalho: Clima e funcionamento organizacional (Fator 1), Pressão no trabalho (Fator 2) e Infraestrutura e rotina (Fator 3). Esse instrumento é composto por 40 itens, cada um com três possibilidades de respostas sobre quanto cada uma das situações de trabalho incomoda o trabalhador: nunca (pontuação 0), às vezes (pontuação 1) e frequentemente (pontuação 2). A vulnerabilidade ao estresse em cada um dos fatores depende da média alcançada (Tabela 2). 
Tabela 2

Classificação da vulnerabilidade ao estresse de acordo com a EVENT.

\begin{tabular}{cccccc}
\hline $\begin{array}{c}\text { Fatores/ } \\
\text { classificação }\end{array}$ & Inferior & Médio inferior & Médio & Médio superior & Superior \\
\hline Fator geral & $\leq 24$ & $23-35$ & 36 & $37-45$ & $\geq 46$ \\
Fator 1 & $\leq 9$ & $10-14$ & 15 & $16-19$ & $\geq 20$ \\
Fator 2 & $\leq 10$ & $11-14$ & 15 & $16-18$ & $\geq 19$ \\
Fator 3 & $\leq 3$ & $4-5$ & 6 & $7-9$ & $\geq 10$ \\
\hline
\end{tabular}

Fonte: Sisto et al., 2007.

Os instrumentos foram aplicados em grupos ou individualmente, nos quatro turnos de trabalho, em uma sala específica, disponibilizada pela direção da UP, sem que houvesse interferência de ruídos ou distrações, conforme instruções previstas no Manual da EVENT. O tempo limite foi de 20 minutos.

Para a realização da pesquisa, que teve a finalidade de compor o trabalho de conclusão do curso de psicologia, a equipe pesquisadora inicialmente fez contato com a unidade prisional, destacando não haver nenhum vínculo entre tal equipe e a instituição pesquisada. Quanto aos aspectos éticos, o projeto de pesquisa foi aprovado pela diretoria geral da UP e, posteriormente, encaminhado para avaliação, aprovação e liberação pela Secretaria de Segurança Pública de Minas Gerais. Obteve-se o parecer favorável circunstanciado do Comitê de Ética e Pesquisa (no 478.899). Os ASP foram convidados a participar da pesquisa concordando em assinar o TCLE.

\section{Análise de dados}

$\mathrm{Na}$ análise dos dados, utilizou-se o software Statistical Package for Social Sciences (SPSS), versão 1.8. Procedeu-se uma análise exploratória dos dados por meio de estatística descritiva, utilizando-se tabelas de frequência e medidas estatísticas, além de gráficos. Foram também adotadas técnicas estatísticas para estimação de médias, comparação de médias, como o teste $\mathrm{T}$ e análise de variância (ANOVA), além de relacionamento de variáveis, como correlação de Pearson e teste de independência (qui-quadrado).

\section{Resultados}

Primeiramente são apresentadas as considerações sobre o perfil sociodemográfico e clínico dos participantes e, posteriormente, os resultados encontrados de acordo com a EVENT. Por fim, relatam-se as relações entre a EVENT e outras variáveis.

\section{Perfil sociodemográfico e clínico}

As características sociodemográficas, clínicas e relacionadas ao trabalho estão descritas na Tabela 3.

Tabela 3

Frequência absoluta (n) e relativa (\%) das características sociodemográficas, clínicas e relacionadas ao trabalho da amostra $(n=95)$.

\begin{tabular}{lcc}
\hline Características & $\mathbf{N}$ & $\mathbf{\%}$ \\
\hline Sociodemográficas & & \\
\hline Sexo & & \\
$\quad$ Masculino & 87 & 91,6 \\
Feminino & 8 & 8,4 \\
$\quad$ Escolaridade & & \\
$\quad$ Médio completo & 72 & 75,8 \\
$\quad$ Superior incompleto & 13 & 13,7 \\
Superior completo & 10 & 10,5 \\
Estado civil & & \\
Casado & 51 & 53,7 \\
Solteiro & 21 & 22,1 \\
União estável & 17 & 17,9 \\
Separado/divorciado & 6 & 6,3 \\
\hline Clínicas & & \\
\hline Uso de medicação continua & & \\
Não & 77 & 81,1 \\
Sim & 18 & 18,9 \\
Vício & & \\
Não & 86 & 90,5 \\
Sim & 9 & 9,5 \\
Tratamento de saúde & & \\
Não & & \\
Sim & 84 & 88,4 \\
Já foi afastado por motivo de & & \\
doença & & \\
Não & & \\
Sim & 70 & 70,7 \\
\hline$\quad$ & 25 & 26,3 \\
\hline
\end{tabular}




\begin{tabular}{lcc}
...continuação & N & \% \\
\hline Características & & \\
\hline Relacionadas ao trabalho & & \\
Tipo de vínculo & 92 & 96,8 \\
Contratado & 3 & 3,2 \\
Concursado & & \\
Função & 29 & 30,5 \\
Plantão & 12 & 12,6 \\
Portaria & 11 & 11,6 \\
GIR & 10 & 10,5 \\
Muralha & 10 & 10,5 \\
GTI & 10 & 10,5 \\
Canil & 6 & 6,3 \\
GTE & 4 & 4,3 \\
Inspetor de plantão & 1 & 1,1 \\
Coordenador de segurança & 1 & 1,1 \\
Externo/obras & 1 & 1,1 \\
Motorista & & \\
\hline
\end{tabular}

Quanto às variáveis clínicas, devem ser ressaltados os seguintes aspectos: uso de medicação contínua (18\%), com destaque para moduladores do sono, remédios clínicos para tratar pressão arterial, antidepressivos, antiepilépticos e ansiolíticos. $\mathrm{O}$ álcool e o tabaco foram as substâncias mais citadas quanto ao vício $(9,5 \%)$. Em relação aos tratamentos de saúde $(11,6 \%)$, os mais declarados pelos entrevistados foram transtornos psiquiátricos, hipertensão e doenças estomacais. Os ASP que declararam já terem sido afastados por motivo de doenças $(26,3 \%)$ informaram como principais causas: estresse, cirurgias, lesões na coluna vertebral, acidente de trabalho, úlcera no estômago e síndrome do pânico.

A Tabela 4 apresenta a média e o desvio padrão das características sociodemográficas e relacionadas ao trabalho da amostra do estudo.
Tabela 4

Média e desvio padrão das características sociodemográficas e relacionadas ao trabalho da amostra estudada $(n=95)$.

\begin{tabular}{lcc}
\hline \multicolumn{1}{c}{ Características } & Média & $\begin{array}{c}\text { Desvio } \\
\text { padrão }\end{array}$ \\
\hline Idade & 36,89 & 6,19 \\
Número de filhos & 1,06 & 0,89 \\
Tempo de exercício na função & 7,88 & 4,41 \\
\hline
\end{tabular}

Vulnerabilidade ao estresse no trabalho

A escala EVENT foi utilizada para avaliar a vulnerabilidade ao estresse dos ASP. De acordo com as instruções e critérios da escala, os resultados podem ser enquadrados nas seguintes categorias: a) quanto ao fator geral: vulnerabilidade ao estresse de maneira geral; b) quanto ao Fator 1: Clima e funcionamento organizacional; c) quanto ao Fator 2: pressão no trabalho; e d) quanto ao Fator 3: infraestrutura e rotina.

O Fator 1 mostra a intensidade com que o ambiente institucional, as relações interpessoais, as relações com as chefias, a liderança, as regras e normas do sistema tornam as pessoas vulneráveis ao estresse; o Fator 2 permite analisar como o trabalhador percebe suas atribuições, funções, características do trabalho, riscos envolvidos, o ambiente e suas responsabilidades; e o Fator 3 permite perceber o quanto a infraestrutura e a rotina da instituição influenciam o comportamento do funcionário a ponto de deixá-lo vulnerável ao estresse (Molina \& Calvo, 2009).

A Tabela 5 comprova o resultado obtido na utilização da EVENT nos fatores com frequência alta nas classificações médio superior e superior, destacando-se o Fator 3 como o de maior índice de vulnerabilidade ao estresse.

Tabela 5

Resultado da EVENT em todos os fatores em relação à amostra pesquisada $(\mathrm{n}=95)$.

\begin{tabular}{ccccccc}
\hline \multirow{2}{*}{ Fator/Classificação } & Inferior & $\begin{array}{c}\text { Médio } \\
\text { inferior }\end{array}$ & Médio & $\begin{array}{c}\text { Médio } \\
\text { Superior }\end{array}$ & Superior & Total \\
\cline { 2 - 6 } & $\mathbf{n ( \% )}$ & $\mathbf{n ~ ( \% )}$ & $\mathbf{n ~ ( \% )}$ & $\mathbf{n ~ ( \% )}$ & $\mathbf{n ~ ( \% )}$ & $\mathbf{n}(\mathbf{\% )}$ \\
\hline Fator geral & $0(0,0)$ & $12(12,6)$ & $6(6,3)$ & $26(27,4)$ & $51(53,7)$ & $95(100,0)$ \\
Fator 1 & $1(1,1)$ & $20(21,1)$ & $5(5,3)$ & $24(25,3)$ & $45(47,4)$ & $95(100,0)$ \\
Fator 2 & $7(7,4)$ & $16(16,8)$ & $11(11,6)$ & $24(25,3)$ & $37(38,9)$ & $95(100,0)$ \\
Fator 3 & $0(0,0)$ & $4(4,2)$ & $3(3,2)$ & $21(22,1)$ & $67(70,5)$ & $95(100,0)$ \\
\hline
\end{tabular}




\section{Vulnerabilidade ao estresse quanto ao fator geral}

Em relação ao fator geral de vulnerabilidade ao estresse para todo o corpo penitenciário da UP, pode-se afirmar que a média está entre 46,23 e 48,77 (IC $=95 \%$ ), pois a média obtida na amostra foi de 47,5 , com $\mathrm{DP}=10,826$. Assim, o nível de vulnerabilidade ao estresse de todos os agentes da UP está enquadrado na categoria superior (acima de 46).

A Tabela 6 demonstra as estatísticas descritivas obtidas tanto do fator geral de vulnerabilidade ao estresse, quanto de cada um dos fatores que compõem o fator geral.

Tabela 6

Estatística descritiva da pontuação dos fatores ( $\mathrm{n}=95)$.

\begin{tabular}{|c|c|c|c|c|c|}
\hline Variáveis & & Fator 1 & Fator 2 & Fator 3 & Fator geral \\
\hline Média & & 19,36 & 17,13 & 11,02 & 47,5053 \\
\hline Mediana & & 19,00 & 17,00 & 11,00 & 47,0000 \\
\hline Moda & & 23 & 15 & 12 & 40,00 \\
\hline Desvio padrão & & 5,537 & 4,489 & 2,993 & 10,82636 \\
\hline Amplitude & & 24 & 22 & 15 & 49,00 \\
\hline Mínimo & & 8 & 4 & 4 & 27,00 \\
\hline Máximo & & 32 & 26 & 19 & 76,00 \\
\hline \multirow{3}{*}{ Percentil } & 25 & 15,00 & 15,00 & 9,00 & 39,0000 \\
\hline & 50 & 19,00 & 17,00 & 11,00 & 47,0000 \\
\hline & 75 & 23,00 & 20,00 & 13,00 & 54,0000 \\
\hline
\end{tabular}

\section{Vulnerabilidade ao estresse no} trabalho de acordo com o Fator 1: Clima e funcionamento organizacional

A média do Fator 1 encontrada para todos os agentes da UP está entre 18,7 e 20,0 (IC = 95\%), o que demonstra que o nível de vulnerabilidade ao estresse médio encontra-se na categoria médio superior (de 16-19) (Tabela 7). Os itens que mais incomodam os trabalhadores são: ambiente físico inadequado (60\%), salário inadequado para a função (58,9\%) e não ser valorizado (56,8\%).

Tabela 7

Itens do questionário (I) referente ao Fator 1.

\begin{tabular}{lccc}
\hline \multicolumn{4}{c}{ (...) Assinale dentre as situações de trabalho o quanto cada uma o incomoda (...) } \\
\hline & $\begin{array}{c}\text { Nunca } \\
\text { n (\%) }\end{array}$ & $\begin{array}{c}\text { Às vezes } \\
\text { n (\%) }\end{array}$ & $\begin{array}{c}\text { Frequentemente } \\
\text { n (\%) }\end{array}$ \\
\hline I3 - Ambiente físico inadequado & $3(3,2)$ & $35(36,8)$ & $57(60,0)$ \\
I4 - Ter autoridade rejeitada pelos iguais ou superiores & $18(18,9)$ & $50(52,6)$ & $27(28,4)$ \\
I5 - Chefes despreparados & $16(16,8)$ & $54(56,8)$ & $25(26,3)$ \\
I6 - Dificuldades pessoais com o chefe & $46(48,4)$ & $39(41,1)$ & $10(10,5)$ \\
I11 - Expectativa excessiva da chefia & $15(15,8)$ & $55(57,9)$ & $25(26,3)$ \\
I13 - Falta de oportunidades de progresso no trabalho & $17(17,9)$ & $50(52,6)$ & $28(29,5)$ \\
I14 - Falta de perspectiva profissional & $25(26,3)$ & $47(49,5)$ & $23(24,2)$ \\
\hline
\end{tabular}

continua... 
...continuação

(...) Assinale dentre as situações de trabalho o quanto cada uma o incomoda (...)

\begin{tabular}{lccc}
\hline & $\begin{array}{c}\text { Nunca } \\
\mathbf{n}(\mathbf{\%})\end{array}$ & $\begin{array}{c}\text { Às vezes } \\
\mathbf{n}(\%)\end{array}$ & $\begin{array}{c}\text { Frequentemente } \\
\text { n (\%) }\end{array}$ \\
\hline I15 - Falta de plano de cargos e salários & $18(18,9)$ & $37(38,9)$ & $40(42,1)$ \\
I16 - Falta de solidariedade & $4(4,2)$ & $45(47,4)$ & $46(48,4)$ \\
I18 - Função pouco conhecida & $12(12,6)$ & $46(48,4)$ & $37(38,9)$ \\
I19 - Impossibilidade de dialogar com a chefia & $27(28,4)$ & $49(51,6)$ & $19(20,0)$ \\
I25 - Não saber como sou avaliado & $5(5,3)$ & $39(41,1)$ & $51(53,7)$ \\
I26 - Não saber quem manda realmente no meu trabalho & $8(8,0)$ & $51(53,7)$ & $36(37,9)$ \\
I27 - Não ser valorizado & $1(1,0)$ & $40(42,1)$ & $54(56,8)$ \\
I36 - Salário inadequado para a função & $16(16,8)$ & $23(24,2)$ & $56(58,9)$ \\
I40 - Tom autoritário de meus superiores & $12(12,6)$ & $55(57,9)$ & $28(29,5)$ \\
\hline
\end{tabular}

Vulnerabilidade ao estresse no trabalho relacionado ao Fator 2: Pressão no trabalho

Quanto ao Fator 2, a média encontrada está entre 16,60 e 17,66 (IC 95\%), significando que esse fator se encontra no nível médio superior (16-18) (Tabela 8). Os itens que mais se destacam são: muita responsabilidade no trabalho diário $(74,7 \%)$, responsabilidade excessiva $(73,7 \%)$ e ritmo acelerado de trabalho $(64,2 \%)$.

Tabela 8

Itens do questionário (I) referente ao Fator 2.

\begin{tabular}{lccc}
\hline \multicolumn{4}{c}{ (...) Assinale dentre as situações de trabalho o quanto cada uma o incomoda (...) } \\
\hline & $\begin{array}{c}\text { Nunca } \\
\text { n (\%) }\end{array}$ & $\begin{array}{c}\text { Às vezes } \\
\text { n (\%) }\end{array}$ & $\begin{array}{c}\text { Frequentemente } \\
\text { n (\%) }\end{array}$ \\
\hline I1 - Acúmulo de funções & $6(6,3)$ & $53(55,8)$ & $36(37,9)$ \\
I2 - Acúmulo de trabalho & $4(4,9)$ & $51(53,7)$ & $40(42,1)$ \\
I12 - Faço trabalho que não pertence a minha função & $21(22,1)$ & $48(50,5)$ & $26(27,4)$ \\
I17 - Fazer trabalho do outro & $3(3,2)$ & $48(50,5)$ & $44(46,3)$ \\
I24 - Muita responsabilidade no trabalho diário & $9(9,5)$ & $15(15,8)$ & $71(74,7)$ \\
I28 - Necessidade de ajudar colegas para fazer o serviço deles & $15(15,8)$ & $46(48,4)$ & $34(35,8)$ \\
I29 - Novas obrigações & $15(15,8)$ & $50(50,2)$ & $30(31,6)$ \\
I30 - O meu erro afeta o trabalho do outro & $12(12,6)$ & $57(60,0)$ & $26(27,4)$ \\
I33 - Prazos para realização de trabalhos & $17(17,9)$ & $51(53,7)$ & $27(28,4)$ \\
I34 - Ritmo acelerado de trabalho & $8(8,4)$ & $26(27,4)$ & $61(64,2)$ \\
I35 - Responsabilidade excessiva & $6(6,2)$ & $19(20,0)$ & $70(73,7)$ \\
I38 - Ter mais obrigações que os demais colegas & $18(18,9)$ & $53(55,8)$ & $24(25,3)$ \\
I39 - Tenho que atender a muitas pessoas de uma só vez & $6(6,3)$ & $46(48,4)$ & $43(45,3)$ \\
\hline
\end{tabular}




\section{Vulnerabilidade ao estresse no trabalho referente ao Fator 3: Infraestrutura e rotina}

O nível de vulnerabilidade ao estresse relacionado ao Fator 3 insere-se na categoria superior
(10 ou mais). A média desse fator está entre 11,37 e 10,67 (IC 95\%) (Tabela 9). As situações de trabalho que mais incomodam nesse fator são: iluminação ambiente (72,6\%), equipamento precário $(63,2 \%)$ e licença de saúde recorrente dos colegas $(34,7 \%)$.

Tabela 9

Itens do questionário (I) referente ao Fator 3.

\begin{tabular}{lccc}
\hline \multicolumn{4}{c}{ (...) Assinale dentre as situações de trabalho o quanto cada uma o incomoda (...) } \\
\hline & $\begin{array}{c}\text { Nunca } \\
\text { n (\%) }\end{array}$ & $\begin{array}{c}\text { Às vezes } \\
\text { n (\%) }\end{array}$ & $\begin{array}{c}\text { Frequentemente } \\
\text { n (\%) }\end{array}$ \\
\hline I7 - Dobrar jornadas & $23(24,2)$ & $57(60,0)$ & $15(15,8)$ \\
I8 - Doença ou acidente pessoal & $56(58,9)$ & $33(34,7)$ & $6(6,3)$ \\
I9 - Equipamento precário & $3(3,2)$ & $32(33,7)$ & $60(63,2)$ \\
I10 - Problemas com a iluminação do ambiente & $5(5,3)$ & $21(22,1)$ & $69(72,6)$ \\
I20 - Licença de saúde recorrente dos colegas & $27(28,4)$ & $35(36,8)$ & $33(34,7)$ \\
I21 - Mudança nas horas de trabalho & $12(12,6)$ & $62(65,3)$ & $21(22,1)$ \\
I22 - Mudança no status financeiro & $28(29,5)$ & $55(57,9)$ & $12(12,6)$ \\
I23 - Mudanças na chefia & $15(15,8)$ & $59(62,1)$ & $21(22,1)$ \\
I31 - Perspectivas de ascensão vinculadas à ideia de & $33(34,7)$ & $47(49,5)$ & $15(15,8)$ \\
transferências & & & $43(45,3)$ \\
I32 - Pouca cooperação da equipe para trabalhos que & $6(6,3)$ & $46(48,4)$ & $1(1,1)$ \\
deveriam ser feitos em conjunto & $86(90,5)$ & $8(8,4)$ & \\
I37 - Salários atrasados & & &
\end{tabular}

\section{Relações entre a EVENT e as variáveis clínicas sociais e laborais dos agentes}

A realização de uma ANOVA da escala EVENT em relação ao estado civil dos ASP constatou que houve diferença significativa ( $p$-valor $=0,001$ ) entre eles. Com o intuito de identificar em que aspecto ocorreu essa distinção, realizou-se um teste de contraste de Tukey, que apontou estar no grupo de solteiros, com pontuação na EVENT de 54,48. Esse grupo é o mais significativamente vulnerável para todos os fatores ( $p$-valor $<0,012$ ), conforme pode ser observado pelas médias da Tabela 10.

Tabela 10

Média da pontuação (ou score) de cada fator por estado civil.

\begin{tabular}{lcccc}
\hline & \multicolumn{3}{c}{ Média } \\
\cline { 2 - 5 } \multicolumn{1}{c}{ Estado civil } & $\begin{array}{c}\text { Clima e } \\
\text { funcionamento } \\
\text { organizacional }\end{array}$ & $\begin{array}{c}\text { Pressão no } \\
\text { trabalho }\end{array}$ & $\begin{array}{c}\text { Infraestrutura e } \\
\text { rotina }\end{array}$ & Fator geral \\
\hline Casado & 19,41 & 16,80 & 11,24 & 47,4510 \\
União estável & 16,65 & 15,65 & 9,24 & 41,5294 \\
Solteiro & 22,14 & 19,81 & 12,52 & 54,4762 \\
Separado/divorciado & 16,83 & 14,67 & 9,00 & 40,5000 \\
\hline
\end{tabular}


No quesito "já foi afastado por motivo de doenças", analisado na entrevista estruturada, o resultado demonstrou que houve diferença significativa ( $p$-valor $=0,067)$ apenas para o Fator 3. Portanto, os ASP da UP que já foram afastados do trabalho por doenças são mais vulneráveis ao estresse quanto à infraestrutura e rotina organizacional, se comparados aos trabalhadores que nunca ficaram afastados pela mesma razão.
Apesar de haver diferenças entre os escores do Fator geral da EVENT em relação às funções de trabalho, conforme demostrado no Gráfico 1, não se pode afirmar que houve diferença significativa ( $p$-valor $=0,424)$. Entretanto, cabe salientar que todas as funções que os ASP ocupam na unidade estudada estão com níveis elevados de vulnerabilidade ao estresse ocupacional.

Figura 1

Gráfico da média do Fator geral por função.

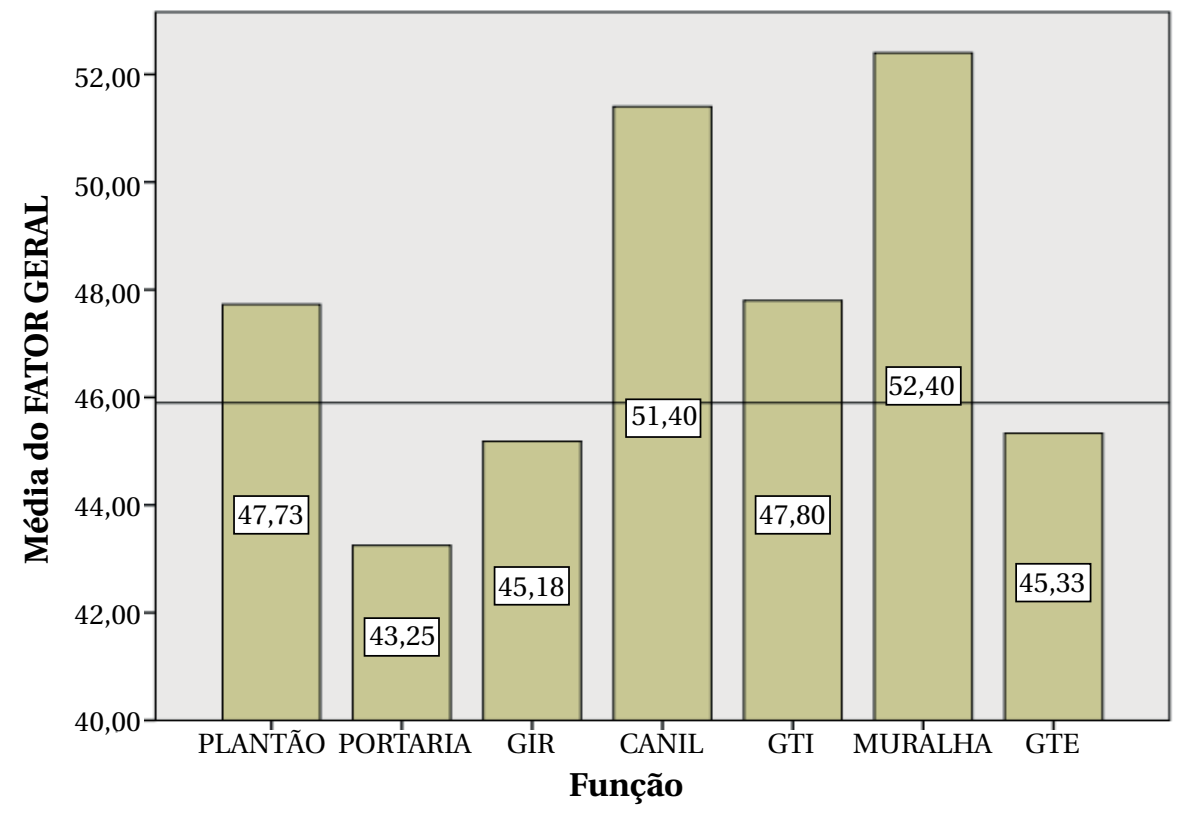

Pelo teste $\mathrm{T}$ realizado, pode-se dizer que não houve diferença significativa da EVENT (Fatores 1, 2, 3 e geral) para as variáveis: uso ou não de medicamentos ( $p$-valor $>0,55$ para todos os fatores); possui ou não possui vícios ( $p$-valor $=0,16$ ); sexo feminino ou masculino ( $p$-valor $>0,18$ para todos os fatores); está ou não em tratamento de saúde ( $p$-valor $>0,11$ para todos os fatores). A respeito do tipo de vínculo (contratado ou concursado), não foi possível realizar o teste de comparação de médias, pois dos 95 ASP, apenas três declararam ser concursados.

Foi aplicada uma ANOVA para verificar se houve diferença significativa entre a escolaridade dos ASP, o que não ocorreu (valor- $p>0,709$ ).

Os estudos também revelaram que não existem correlações significativas entre EVENT e idade ( $p$-valor $>0,242)$ e entre EVENT e número de filhos ( $p$-valor $>0,109$ ), tanto para a pontuação total quanto para os três fatores. Assim, a vulnerabilidade ao estresse no ASP independe da idade e da quantidade de filhos.

Não existem diferenças significativas a serem consideradas no que concerne à relação entre a EVENT e o tempo de exercício na função ( $p$-valor $>0,357$ ), demonstrando que a vulnerabilidade ao estresse pode manifestar-se no ASP independentemente do tempo em que o profissional exerce suas funções na UP.

\section{Discussão}

É de fundamental importância salientar que realizar pesquisa em uma instituição prisional é uma tarefa árdua, permeada por desafios inerentes ao próprio ambiente laborativo. Por se tratar de um ambiente fechado e por ser uma instituição prisional, os dias das coletas de dados foram agendados previamente com a direção, de maneira que, no final de cada um deles, a diretoria planejava outra data 
para o retorno da pesquisadora. Isso se deve ao fato de que o ritmo do trabalho na UP é intenso, e o trabalhador recebe intensas solicitações, sendo constantemente demandado.

Por vezes, por mais que fosse agendada a coleta com programação preliminar, objetivando aplicar os instrumentos no maior número de ASP possível, o dia era finalizado com pouquíssimos testes aplicados, e em outras situações, sem qualquer abordagem. Como não podem abandonar seus postos de trabalho sem que outros os cubram, os ASP eram disponibilizados paulatinamente. Ademais, em diversas circunstâncias, esse trabalhador não podia abandonar o posto em razão de situações peculiares a quem trabalha em um cárcere: desentendimentos entre os detentos, tentativas de fuga dos presos, verificação de possível existência de objetos ilícitos no interior das celas, ou até mesmo o próprio clima de tensão entre os presos. Essas situações exigiam que a direção mantivesse toda a equipe penitenciária em estado de alerta para cumprir o propósito de segurança da UP.

Destaca-se, assim, que uma das maiores dificuldades de realizar pesquisas nessa área, principalmente no interior de UP, pelo caráter de instituição fechada, consiste nas restrições relacionadas à segurança, como limites à circulação e ao acesso a determinados espaços, além de resistência à entrada de indivíduos externos ao sistema.

Bezerra, Assis e Constantino (2016), entre os anos de 2000 e 2014, realizaram um levantamento acadêmico, nos periódicos nacionais e internacionais, sobre sofrimento psíquico e estresse no trabalho de ASP. Tendo como base de dados a Biblioteca Virtual em Saúde, a Web of Science e a base Scopus, e usando como principais descritores "sofrimento psíquico", "estresse" e "agentes penitenciários", os pesquisadores concluíram que o país que mais publica sobre o tema são os Estados Unidos, havendo pouco destaque nas revistas de saúde pública. Na América Latina, foram encontrados quatro estudos, todos brasileiros e inseridos em publicações sobre saúde Psicologia Ciência e Profissão, Estudos Psicológicos e Cadernos de Saúde Pública. Os achados da referida pesquisa elencaram como fatores de risco, trabalho intenso, falta de infraestrutura e de recursos humanos, contato com os detentos, superlotação, percepções sobre medo ou perigo, paradoxo punir/reeducar, entre outros. O estudo demostrou que os fatores protetivos estão ligados ao apoio social no interior da UP, que os mecanismos de enfrentamento consistem na formação continuada dos ASP, no encorajamento ao suporte social e no atendimento psicológico. Também identificou que, embora as pesquisas sobre estresse e sofrimento psíquico entre ASP tenham aumentado gradativamente, ainda se carece de investigações frente ao aumento constante do número de UP nos países.

Ao realizar uma pesquisa em base de dados, foi encontrado um estudo (Molina \& Calvo, 2009) no Brasil que utilizou a EVENT para avaliar o estresse no ASP. Tal estudo investigou a vulnerabilidade ao estresse no trabalho de 59 ASP locados em setores da Penitenciária de Tupi Paulista. Os resultados apontaram que $15 \%$ dos funcionários estavam no nível superior de vulnerabilidade e 33\% no nível médio superior. Parte significativa da população pesquisada apresentava vulnerabilidade quanto à infraestrutura e rotina no trabalho. Além disso, os fatores relacionados ao clima organizacional demonstraram colaborar para o descontentamento e a falta de motivação dos funcionários.

Já nos resultados do presente estudo, a vulnerabilidade foi superior em 51 ASP (53,7\%) e médio superior em 26 (27,4\%), totalizando mais de $81 \%$ dos trabalhadores com níveis de vulnerabilidades superior e médio superior. Percebe-se que, nos estudos de Molina e Calvo (2009), a vulnerabilidade ao estresse não foi tão elevada se comparada aos resultados da presente pesquisa.

Ao refletir sobre as diferenças encontradas entre os estudos, são lançadas algumas hipóteses que tentam explicá-las. Um dos fatores que pode justificar os resultados não similares decorre das realidades díspares entre o contexto laboral de um trabalhador de uma unidade de detenção provisória e de uma penitenciária. Consoante os dados divulgados pelo último Levantamento Nacional de Informações Penitenciárias (Infopen) sobre a população carcerária no Brasil, realizado em 2016, foi constatado um grande crescimento da população carcerária, ultrapassando a marca dos 700 mil, o que representa um aumento de $707 \%$ em relação ao total da população no início da década de 1990. O estudo expôs que a taxa de aprisionamento no país aumentou em $157 \%$ entre os anos de 2000 e 2016. O número de presos é consideravelmente superior às 358.663 vagas do sistema penitenciário. O censo ainda elucidou que essa superlotação é destinada ao tipo de regime de presos provisórios (Santos \& Rosa, 2017b). 
Segundo o Conselho Nacional de Justiça (Brasil, 2018) em agosto de 2018 havia 602.217 pessoas privadas de liberdade no Brasil, e desse total, 40,03\% eram provisórios. Assim, considerando a atual situação da UP pesquisada como uma instituição que abriga presos provisórios, é possível refletir sobre os possíveis impactos do aumento da população carcerária na saúde dos ASP. Consoante o entendimento de Lopes (2002) e Rumin (2006), o número excedente de sentenciados pode gerar sobrecarga de trabalho e, consequentemente, o surgimento de doenças, tais como o estresse.

Ao comparar os resultados encontrados em cada um dos fatores da EVENT, no presente estudo, com os achados de Molina e Calvo (2009), percebemos que, quanto ao Fator 1, Clima e funcionamento organizacional, a vulnerabilidade ao estresse dos agentes da UP foi classificada como médio superior, dado que corrobora os resultados de Molina e Calvo. No Fator 2, Pressão no trabalho, os resultados demonstram que a vulnerabilidade foi classificada como médio superior, diferenciando-se dos resultados da pesquisa na Penitenciária de Tupi Paulista, a qual apresentou uma média na vulnerabilidade mais baixa no fator, ou seja, abaixo de $50 \%$ (Tabela 11).

O Fator 1 demonstra o quanto o ambiente institucional, as relações entre os colegas e chefias e a insatisfação com o trabalho influenciam os trabalhadores ao ponto de os deixarem vulneráveis ao estresse. Os resultados da presente pesquisa demostraram que o ambiente de trabalho é um dos responsáveis pela suscetibilidade ao estresse dos ASP, sendo que tal questão também foi apontada por outros autores no contexto prisional (Bonez et al., 2013; Cruz et al., 2013; Lopes, 2002; Lourenço, 2010; Saldaña et al., 2010) e confirmada em pesquisas similares (Molina \& Calvo, 2009).

\section{Tabela 11}

Comparação em percentual da classificação da EVENT entre a unidade prisional estudada e a Penitenciária Tupi Paulista.

\begin{tabular}{lcccccc}
\hline Fatores/ classificação & Inferior (\%) & $\begin{array}{c}\text { Médio } \\
\text { inferior (\%) }\end{array}$ & Médio (\%) & $\begin{array}{c}\text { Médio } \\
\text { superior (\%) }\end{array}$ & Superior (\%) & Total (\%) \\
\hline Fator geral & 0 & 12,6 & 6,3 & 27,4 & 53,7 & 100 \\
$\quad$ UP interior MG & 34 & 9 & 9 & 33 & 15 & 100 \\
P. Tupi Paulista & & & & & & \\
Fator 1 & 1,1 & 1,1 & 5,3 & 25,3 & 47,4 & 100 \\
UP interior MG & 31 & 34,5 & 5,2 & 8,6 & 20,7 & 100 \\
P. Tupi Paulista & & & & & & \\
Fator 2 & 7,4 & 16,8 & 11,6 & 25,3 & 38,9 & 100 \\
UP interior MG & 27 & 26 & 9 & 26 & 12 & 100 \\
P. Tupi Paulista & & & & & & 100 \\
Fator 3 & 0 & 4,2 & 3,2 & 22,1 & 70,5 & 100 \\
UP interior MG & 31 & 12 & 7 & 40 & 10 & \\
P. Tupi Paulista & & & & & & \\
\hline
\end{tabular}

O mesmo pode ser observado em relação ao fator F, Pressão no trabalho, uma vez que o resultado encontrado neste estudo condiz com as considerações expressadas por estudiosos do assunto (Correia, 2006; Duarte, 2010; Fernandes et al., 2002; Rumin, 2006; Saldaña et al., 2010), além de confirmar os achados em pesquisas similares (Molina \& Calvo, 2009).
Atribuindo os baixos índices no Fator 2 à internalização da pressão como sendo característica da função de ASP, Molina e Calvo (2009) sugeriram, em sua pesquisa, que os trabalhadores perceberam a pressão no trabalho como sendo normal no cotidiano. Entretanto, nos profissionais da UP do interior de Minas Gerais, esse item apresentou grande relevância, 
demostrando que os ASP podem perceber as características de sua função e suas responsabilidades como extremas e inadequadas ao ponto de deixá-los vulneráveis ao estresse.

$\mathrm{Na}$ terceira variável, Infraestrutura e rotina, a vulnerabilidade ao estresse foi classificada no índice mais alto, ou seja, nível superior. Dos 95 ASP, $67(70,5 \%)$ estão com a pontuação média superior. Tal índice aponta para um dado relevante: mais da metade $(70,5 \%)$ dos ASP da UP foram classificados no nível superior de vulnerabilidade ao estresse quanto ao Fator 3. A estrutura física organizacional, instalações e atividades regidas por normas já foram sinalizadas por outros estudiosos como fatores estressantes (Araújo Filho, 2010; Lourenço, 2010; Saldaña et al., 2010; Tschiedel \& Monteiro, 2013), e reforçadas por pesquisas similares (Molina \& Calvo, 2009).

Lourenço (2010), em sua tese de doutorado, realizou uma pesquisa com ASP para verificar as relações individuais e grupais no ambiente prisional. Nesse estudo, foi observado que o ambiente prisional é perigoso, insalubre e com estrutura física inadequada, podendo acarretar vitimização dos trabalhadores e dos internos. Verificou-se também que os ASP se incomodam com a condição inadequada de trabalho, que por sua vez leva à precarização da própria existência pessoal dos agentes.

Nesse contexto, os resultados encontrados nesta pesquisa condizem com os de outros trabalhos. Fernandes et al. (2002) realizaram um estudo epidemiológico transversal para identificar possíveis associações entre condições de trabalho e saúde dos ASP de Salvador (BA). Para tanto, utilizaram o Inventário de Sintomas de Stress (ISS) como instrumento para identificar se o indivíduo apresentava sintomas de estresse, o tipo de sintoma e em que fase se encontrava. Como resultados, constataram que o ambiente laboral psicologicamente inadequado, aliado às condições infraestruturais insuficientes, à ausência de lazer e de esporte, entre outros fatores inerentes à função, foi associado a distúrbios psíquicos menores (DPM) e sintomas de estresse persistente.

Corroborando os dados apresentados anteriormente, Santos (2007) realizou uma pesquisa com 564 ASP do estado do Paraná. O estudo revelou o estresse como um dos grandes males atuais na classificação dos distúrbios emocionais que afeta os agentes, e ratificou a profissão como de altíssimo grau estressante, além da estabelecida natureza penosa, perigosa e insalubre.
No mesmo sentido, nos estudos de Rocha (1999), $81 \%$ dos ASP pesquisados enquadravam-se em parâmetros de grave a gravíssimo no que se refere às consequências acarretadas pelo estresse, apresentando sérios problemas referentes à atenção, concentração, capacitação física, entre outros.

No Rio Grande do Sul, Tschiedel e Monteiro (2013) pesquisaram ASP femininas e utilizaram entrevistas semiestruturadas. Entre os achados, apontaram que a vivência de sofrimento psíquico está relacionada ao contexto da organização, bem como às condições e relações de trabalho. Concluíram que as profissionais estudadas tentam encontrar caminhos para manter a saúde, enfrentar o sofrimento e buscar prazer. Na pesquisa, sobressaíram-se alguns fatores consideráveis de sofrimento, sobretudo relacionados às condições precárias de trabalho e às cobranças sem apoio ou respaldo da instituição.

Essas observações condizem com o presente estudo, pois a vulnerabilidade ao estresse foi classificada como superior em um contexto geral (Fator geral), médio superior no Fator 1 e 2 e superior no Fator 3. Tais dados, além de revelarem insatisfação quanto a algumas condições de trabalho que podem favorecer o surgimento de doenças, demostram que os funcionários da UP estão em situação de vulnerabilidade extrema, necessitando de medidas de combate aos efeitos do estresse.

Outro dado que demostrou grande relevância diz respeito ao tipo de vínculo de trabalho dos funcionários da UP. Os resultados demostraram que $92(96,8 \%)$ ASP são contratados e somente $3(3,2 \%)$ são concursados ou efetivos. Esses achados condizem com outros estudos (Cruz et al., 2013; Lourenço, 2010). Na pesquisa de Lourenço, os resultados foram: 66 (72\%) ASP eram contratados e 25 (28\%) eram efetivos. Refletindo sobre essa circunstância, o autor pontua que esse tipo de vínculo de trabalho pode levar a incertezas decorrentes da condição de temporário e motivar grande número de queixas por parte do trabalhador. Dados do Infopen de junho de 2014 revelaram que, no Brasil, um em cada cinco trabalhadores penitenciários são temporários. Espírito Santo, Goiás, Minas Gerais e Pará foram os estados da federação que apresentaram maioria nesse vínculo empregatício. Discutindo sobre essa problemática, Cruz et al. (2013) denotam que o desequilíbrio gerado entre os vínculos de trabalho modifica a liderança do processo de trabalho em uma prisão, o que somado à superlotação das celas aumenta o déficit de trabalhadores no sistema, afetando todos os procedimentos internos da unidade. 
Em relação à bibliografia consultada, não foram encontradas discussões que promovessem reflexão sobre o fato de os solteiros serem mais vulneráveis ao estresse do que as demais categorias de estado civil elencadas, merecendo por sua vez uma investigação específica a esse propósito, ficando, assim, como sugestão para pesquisas e análises futuras. Essa constatação suscita reflexões sobre a importância do suporte familiar na redução de danos ao estresse em diversos contextos, inclusive no âmbito laboral. Para Baptista (2005), o suporte familiar pode ser considerado um dos mais relevantes amortecedores de diversos estressores na vida das pessoas.

Na esfera do desenvolvimento humano, a família, que ocupa lugar privilegiado no processo saúde-doença, representa o eixo de organização do espaço social imediato dos indivíduos, facilitando seu ajuste às dificuldades da vida. Nesse sentido, a partir do âmbito familiar, é possível observar mecanismos de risco-proteção à saúde (Bastos \& Trad, 1998).

Outro elemento explorado nas relações entre as variáveis e a EVENT foi o item da entrevista estruturada Já foi afastado por motivo de doenças. A análise dos resultados permitiu observar que houve diferença significativa para o elemento Infraestrutura e rotina (Fator 3). De igual modo, não foram encontrados estudos passíveis de comparação relacionando essa variável à vulnerabilidade ao estresse do ASP.

Na pesquisa de Bonez et al. (2013) sobre as variáveis que interferem na saúde mental dos ASP, o estresse foi um dos fatores estudados. Os resultados apontaram que esse fenômeno não controlado pode ocasionar afastamento dos agentes de seu ambiente de trabalho. Nessa dimensão, Moraes (2013) reflete sobre o elevado estresse e seus reflexos negativos, físicos e psíquicos entre os ASP do Departamento Penitenciário do estado do Paraná. Na pesquisa do autor, o impacto do trabalho no ambiente prisional sobre a vida dos ASP foi evidenciado em muitas respostas a perguntas que eram direcionadas aos agentes, como: "A prisão mudou você?" e "Você teve algum problema de saúde que possa dizer que foi gerado pelo trabalho na prisão?”. Segundo o autor, em relação à primeira pergunta, foram obtidas as mais diferentes respostas, ora positivas, ora negativas, geralmente com referências à identificação que o ASP tinha com o preso ou à emergência de percepções de mundo e de si mesmos. Já em relação à segunda, os ASP tiveram mais facilidade para falar sobre as doenças físicas do que as psicológicas.
Nos achados de Cruz et al. (2013), as queixas dos ASP a respeito da realidade das UP foram preponderantes. As ameaças dos presos, os sentimentos de insegurança gerados pela atividade e a falta de suporte da direção foram apontados como causas de sofrimento psíquico no exercício profissional. Os autores ressaltaram que diversos agentes justificaram as faltas aos dias de trabalho como mecanismo de defesa contra as insatisfações percebidas no contexto organizacional. Nesse sentido, salientam a relevância da assistência psicológica ao ASP e a destacam como um quesito que necessita de correção.

Outros dados obtidos dão suporte à literatura existente. Conforme já apontado, ao realizar uma ANOVA, percebeu-se que não houve diferença significativa entre os fatores da EVENT e o tipo de função dos ASP. Entretanto, quando se utiliza o critério da EVENT com a análise por meio do gráfico de barras, pode-se perceber classificação distinta do nível de vulnerabilidade ao estresse entre as funções desempenhadas pelos agentes. Vale aqui salientar que não foram encontrados em bases de pesquisas brasileiras - Literatura LatinoAmericana e do Caribe em Ciências da Saúde (LILACS) e Scientific Eletronic Library Online (SciELO) - estudos que investigassem descritivamente as funções desempenhadas pelos ASP, relacionando-as à vulnerabilidade ao estresse. Entretanto, segundo dados da Organização Mundial da Saúde (Leka et al., 2003), diferentes tipos de função ou cargo podem favorecer mais ou menos o estresse no trabalho, fato também já debatido por outros estudiosos (Chiavenato, 2004; Greenberg, 2002; Robbins, 2002; Sisto et al., 2007; Sousa et al., 2009; Stoner \& Freeman, 1999; Zanelli, 2010).

\section{Considerações finais}

Concluiu-se com o estudo que os Agentes de Segurança Penitenciários da Unidade Prisional do interior de Minas Gerais estudados estão vulneráveis ao estresse, devendo ser elaboradas políticas públicas para combater esse fenômeno. A problemática não se limita a uma única área, perpassando as esferas humanitária, social e ético-política.

Foi possível refletir que a vulnerabilidade ao estresse do ASP está relacionada às condições do trabalho e ao próprio sistema, uma vez que as atuais condições carcerárias, marcadas pela superlotação, influenciam na saúde dos trabalhadores penitenciários.

Um dado muito relevante apontado pela presente pesquisa é que os ASP solteiros apresentaram maior 
vulnerabilidade ao estresse, o que traz uma possível reflexão sobre o suporte familiar ser uma valiosa ferramenta para redução de danos causados pelo estresse. Sendo assim, as políticas públicas para os servidores penitenciários devem ter também como ponto de apoio o estímulo ao convívio familiar e outras estratégias que fortaleçam esse importante vínculo.

Estudar o estresse no trabalho é uma tarefa infindável, haja vista o que já foi problematizado por estudiosos e pesquisadores. Entretanto, ao adentrar em um ambiente de trabalho tão peculiar quanto uma UP, constata-se a necessidade de realçar a função do ASP, um profissional de valor encoberto na manutenção da ordem do sistema. O estabelecimento prisional, como instituição fechada, tem caráter singular e pode causar no expectador, externo a esses muros, o anelo de compreender sua cultura, sua visão organizacional e o espaço ocupado pelo ASP nesse contexto. Nesse sentido, ao avaliar a vulnerabilidade ao estresse desses trabalhadores, não se pode ignorar o ambiente e o atual quadro brasileiro de crescimento da população carcerária como fatores que influenciam suas atividades laborais, as quais, somadas às características pessoais e organizacionais, contribuem para o adoecimento dentro dessas muradas.

Certas mudanças que aqui poderiam ser propostas perpassam o nível acadêmico e social e chegam ao patamar de políticas públicas penais e penitenciárias, tais como: espaço físico adequado ao número de detentos; ambientes institucionais mais salubres; redução da jornada de trabalho dos ASP, entre outros. $O$ estudo também possibilitou perceber a necessidade de se buscar apoio psicológico para os profissionais em questão, melhorias quanto aos relacionamentos entre os pares e superiores, além do desenvolvimento de planos de ação e motivação para o profissional. Assim, devem ser criadas estratégias relacionadas ao clima da organização, à pressão no trabalho e à infraestrutura e rotina da unidade.

No sistema penitenciário, muito se apontam as falhas que afetam a vida do encarcerado. Entretanto, é possível verificar que os desafios encontrados refletem também sobre o trabalhador, e que as alternativas existentes para a superação dessas demandas ainda não são suficientes.

Assim, espera-se que este estudo possa ser útil como mecanismo de apoio para futuras decisões organizacionais no que concerne às evidências encontradas, contribuindo com melhorias para a categoria profissional. Além disso, espera-se que os resultados aqui apresentados proporcionem reflexões acerca da temática em questão, suscitando que sejam colocadas em prática na UP novas propostas, para oferecer melhor qualidade de vida laboral aos ASP que lutam por seu reconhecimento.

\section{Referências}

Andrade, J. S. (2013). Estresse ocupacional, hardiness e qualidade de vida profissional de policiais militares de uma cidade do interior de Mato Grosso do Sul [Dissertação de mestrado]. Universidade Católica de Dom Bosco.

Araújo Filho, J. B. (2010). Ocorrência de estresse ocupacional nos servidores da segurança pública [Trabalho de conclusão de curso, Universidade Estadual da Paraíba]. Biblioteca Digital da UEPB. http://dspace.bc.uepb.edu.br/ jspui/handle/123456789/544

Baptista, M. N. (2005). Desenvolvimento do Inventário de Percepção de Suporte Familiar (IPSF): Estudos psicométricos preliminares. Revista Psico - USF, 10(1), 1119.

Bastos, A. C. S., \& Trad, A. B. (1998). A família enquanto contexto de desenvolvimento humano: Implicações para a investigação em saúde. Ciência e Saúde Coletiva, 3(1), 106115. https://doi.org/10.1590/1413-812319983100272014

Bezerra, C. M., Assis, S. G., \& Constantino, P. (2016). Sofrimento psíquico e estresse no trabalho de agentes penitenciários: Uma revisão da literatura. Ciência e Saúde Coletiva, 21(7), 21352146. https://doi.org/ $10.1590 / 1413-81232015217.00502016$

Bonez, A., Sehnem, S. B., \& Moro, E. D. (2013). Saúde mental de agentes penitenciários de um presídio catarinense. Psicologia Argumento, 31(74), 507517. http://dx.doi.org/10.7213/psicol.argum.31.074.AO05

Brasil. (2018). Banco Nacional de Monitoramento de Prisões. Conselho Nacional de Justiça: Cadastro Nacional de Presos. Supremo Tribunal Federal.

Chiavenato, I. (2004). Gestão de pessoas: O novo papel dos recursos humanos nas organizações (7a reimp.). Campus.

Codo, W., Saratto, L., \& Vasquez-Menezes, I. (2004). Saúde Mental e trabalho. In J. C. Zanelli, J. E. Borges-Andrade, \& A. V. B. Bastos (Orgs.), Psicologia, organizações e trabalho no Brasil (p. 277299). Artmed. 
Psicologia: Ciência e Profissão 2021 v. 41nspe2, e197193, 1-18.

Correia, A. P. (2006). Uma análise dos fatores de risco da profissão do agente penitenciário: Contribuições para uma política de segurança e saúde na gestão penitenciária [Trabalho de conclusão de curso]. Universidade Federal do Paraná.

Cruz, M. V. G., Batitucci, E. C., Silva, S. L. F., \& Souza, L. G. (2013, 23-27 de setembro). Agente Penitenciário: em busca da identidade - notas de pesquisa no sistema prisional de Minas Gerais. 37o Encontro Anual da ANPOCS, Águas de Lindoia, SP, Brasil.

Duarte, C. L. (2010). O papel do agente prisional na ressocialização do preso [Trabalho de conclusão de curso, Universidade Federal de Minas Gerais]. Repositório Institucional da UFMG. https://repositorio.ufmg.br/ handle/1843/BUOS-9BDHFJ

DuBrin, A. J. (2003). Fundamentos do Comportamento Organizacional. Pioneira Thomson Learning.

Fernandes, R. C. P., Silvany Neto, A. M., Sena, G. M., Leal, A. S., Carneiro, C. A. P., \& Costa, F. P. M. (2002). Trabalho e cárcere: Um estudo com agentes penitenciários da Região Metropolitana de Salvador, Brasil. Cadernos de Saúde Pública, 18(3), 807816. https://doi.org/10.1590/S0102-311X2002000300024

Genuíno, S. L. V. P., Gomes, M. S., \& Moraes, E. M. (2009). O Estresse Ocupacional e a Síndrome de Burnout no ambiente de trabalho: Suas influências no comportamento dos professores da rede privada do Ensino Médio de João Pessoa. Anagrama, 3(2), 19.

Goulart Júnior, E., \& Lipp, M. E. N. (2011). Estilo de liderança e stress: Uma pesquisa em escolas estaduais de ensino fundamental. Revista Brasileira de Política e Administração da Educação, 27(2), 265283. https://doi.org/10.21573/ vol27n22011.24773

Greenberg, J. S. (2002). Administração do Estresse. Manole.

Guimarães, L. A. M., \& Freire, H. B. G. (2004). Sobre o estresse ocupacional e suas repercussões na saúde. In L. A. M. Guimarães, \& S. Grubits (Orgs.), Série saúde mental e trabalho (vol. 2, pp. 2954). Casa do Psicólogo.

Kurowski, C. M., \& Moreno-Jiménez, B. (2002). A Síndrome de Burnout em funcionários de instituições penitenciárias. In A. M. T. Benevides-Pereira (Org.), Burnout: Quando o trabalho ameaça o bem-estar do trabalhador (pp. 213226). Casa do Psicólogo.

Ladeira, M. B. (1996). O processo do stress ocupacional e a psicopatologia do trabalho. Revista de Administração da Universidade de São Paulo, 31(1), 6474.

Leka, S., Griffiths, A., \& Cox, T. (2003). La organización del trabajo y el estrés: Estrategias sistemáticas de solución de problemas para empleadores, personal directivo y representantes sindicales. World Health Organization.

Lopes, R. (2002). Psicologia jurídica o cotidiano da violência: $\mathrm{O}$ trabalho do agente de segurança penitenciária nas instituições prisionais. Psicologia para América Latina.

Lourenço, A. S. (2010). O espaço de vida do Agente de Segurança Penitenciária no cárcere: Entre gaiolas, ratoeiras e aquários [Tese de doutorado, Universidade de São Paulo]. Biblioteca Digital de Teses e Dissertações da USP. https://www.teses.usp.br/teses/disponiveis/47/47134/tde-20072010-153506/pt-br.php

Molina, C., \& Calvo, E. A. (2009, 24-26 de setembro). Doenças ocupacionais: Um estudo sobre o estresse em agentes penitenciários de uma unidade prisional. Encontro de Iniciação Científica, 5(5).

Moraes, P.R. B. (2013). A identidade e o papel de agentes penitenciários. Tempo Social, 25(1), 131147.https://doi.org/ $10.1590 /$ S0103-20702013000100007

Paschoal, T., \& Tamayo, A. (2004). Validação da escala de estresse no trabalho. Estudos de Psicologia (Natal), 9(1), 455. https://doi.org/10.1590/S1413-294X2004000100006

Reis, A. L. P. P., Fernandes, S. R. P., \& Gomes, A. F. (2010). Estresse e fatores psicossociais. Psicologia: Ciência e Profissão, 30(4), 712725. https://doi.org/10.1590/S1414-98932010000400004

Robbins, S. P. (2002). Comportamento organizacional. Pearson Prentice Hall.

Rocha, E. V. (1999). Stress em agentes penitenciários [Artigo apresentado]. $3^{\circ}$ Congresso Íbero-Americano de Psicologia Jurídica, São Paulo, SP, Brasil.

Rumin,C. R. (2006). Sofrimento na vigilância prisional: O trabalho e a atenção em saúde mental. Psicologia: Ciência e Profissão, 26(4), 570581. https://doi.org/10.1590/S1414-98932006000400005

Saldaña, A. T., Menotti, I. S., Garavito, C. S., \& Muñoz, D. A. (2010). Problemáticas psicossociales en guardianes penitenciários: Riesgos y prevención. Universidad Santo Tomáz. 
Salla, F., Dias, C. N., \& Silvestre, G. (2012). Políticas penitenciárias e as facções criminosas: Uma análise do Regime Disciplinar Diferenciado (RDD) e outras medidas administrativas de controle da população carcerária. Revista Estudos de Sociologia, 17(33), 333351.

Santos, J. R. R. (2007). O fenômeno da prisionização em agentes penitenciários do estado do Paraná [Trabalho de conclusão de curso]. Universidade Federal do Paraná.

Santos, T., \& Rosa, M. I. (2017a). Levantamento Nacional de Informações Penitenciárias: INFOPEN - dezembro de 2015. Ministério da Justiça e Segurança Pública. Departamento Penitenciário Nacional.

Santos, T., \& Rosa, M. I. (2017b). Levantamento Nacional de Informações Penitenciárias: INFOPEN-junho de 2016. Ministério da Justiça e Segurança Pública. Departamento Penitenciário Nacional.

Sisto, F. F., Baptista, M. N., \& Noronha, A. P. P. (2007). Escala de Vulnerabilidade ao Estresse no Trabalho Coleção EVENT. Vetor.

Sousa, I. F., Mendonça, H., Zanini, D. S., \& Nazareno, E. (2009). Estresse Ocupacional, Coping e Burnout. Estudos, 36(1), 5774.

Stoner, J. A. F., \& Freeman, R. E. (1999). Administração (5a ed.). LTC.

Tschiedel, R. M., \& Monteiro, J. K. (2013). Prazer e sofrimento no trabalho das agentes de segurança penitenciária. Estudos de Psicologia, 18(3), 527535. https:/ / doi.org/10.1590/S1413-294X2013000300013

Zanelli, J. C. (2010). Estresse nas organizações de trabalho: Compreensão e intervenção baseadas em evidências. Artmed.

Sara Rodrigues de Jesus

Psicóloga. Pós-Graduanda em Gestão da Saúde pela Universidade Estácio de Sá, Rio de Janeiro - RJ. Brasil.

E-mail: sarajesuss@hotmail.com

(1) https://orcid.org/0000-0003-3145-5481

\section{Andreia Monteiro Felippe}

Mestre em Psicologia pela Universidade Federal de Juiz de Fora. Professora do Centro Universitário Academia, Juiz de Fora - MG. Brasil.

E-mail: andreiafelippe@uniacademia.edu.br

(1) https://orcid.org/0000-0001-9155-8840

Yury Vasconcellos da Silva

Mestre em Estatística pela Universidade Federal de Viçosa. Professor do Centro Universitário Academia, Juiz de Fora - MG. Brasil.

E-mail: yury@grupovasconcellos.com.br

(1) https://orcid.org/0000-0003-2434-7036

Agradecimentos à Secretaria de Estado de Administração Prisional de Minas Gerais (SEAP/MG), atual Secretaria de Estado de Justiça e Segurança Pública de Minas Gerais (SEJUSP/MG), e à Direção da Unidade Prisional do interior de Minas Gerais por autorizarem e viabilizarem a realização da pesquisa.

Endereço para envio de correspondência:

Centro Universitário Academia, Departamento de Psicologia. Rua Halfeld, 1179, Centro. CEP: 36016-000. Juiz de Fora-MG. Brasil. 
Psicologia: Ciência e Profissão 2021 v. 41nspe2, e197193, 1-18.

Recebido 01/05/2018

Aceito 21/08/2019

Received 05/01/2018

Approved 08/21/2019

Recibido 01/05/2018

Aceptado 21/08/2019

Como citar: Jesus, S. R., Felippe, A. M., Silva, Y.V. (2021). Vulnerabilidade ao estresse em Agentes de Segurança Penitenciários. Psicologia: Ciência e Profissão, 41, 1-18. https://doi.org/10.1590/1982-3703003197193

How to cite: Jesus, S. R., Felippe, A. M., Silva, Y. V. (2021). Vulnerability to Stress in Penitentiary Security Agents. Psicologia: Ciência e Profissão, 41, 1-18. https:// doi.org/10.1590/1982-3703003197193

Cómo citar: Jesus, S. R., Felippe, A. M., Silva, Y. V. (2021). Vulnerabilidad al Estrés en los Agentes de Seguridad Penitenciarios. Psicologia: Ciência e Profissão, 41, 1-18. https://doi.org/10.1590/1982-3703003197193 